\title{
Predictors of Perceived Social Support for Patients with Dementia: A Mixed-Methods Study
}

This article was published in the following Dove Press journal:

Clinical Interventions in Aging

\author{
Siyuan Yang (D) \\ Yunmei Zhang ${ }^{2}$ \\ Shiqi Xie ${ }^{2}$ \\ Yanhan Chen ${ }^{2}$ \\ Dengbi Jiang ${ }^{3}$ \\ Yetao Luo ${ }^{4}$ \\ Qinghua Zhao' \\ Bing Yang $(\mathbb{D})^{2}$ \\ 'Nursing Department, The First Affiliated \\ Hospital of Chongqing Medical University, \\ Chongqing, Yuzhong District, People's \\ Republic of China; ${ }^{2}$ School of Nursing, \\ Chongqing Medical University, \\ Chongqing, Yuzhong District, People's \\ Republic of China; ${ }^{3}$ Community Health \\ Center of Daxigou, Chongqing, Yuzhong \\ District, People's Republic of China; \\ ${ }^{4}$ Department of Biostatistics, School of \\ Public Health and Management, \\ Chongqing Medical University, \\ Chongqing, Yuzhong District, People's \\ Republic of China
}

Correspondence: Bing Yang; Qinghua

Zhao

Email yangb@hospital.cqmu.edu.cn; qh20063@163.com
Purpose: Perceived social support (PSS) is closely linked to health outcomes in dementia patients. However, its continuous benefits are unclear. This mixed-methods study examined the impact of social support perceptions and differentiation among patients and carers during disease progression.

Patients and Methods: Persons with dementia (PWDs), family caregivers, and community family physicians were recruited from nine community health centers. Semi-structured interviews conducted with 12 PWDs (7 PWDs in mild dementia and 5 in moderate dementia), 12 family caregivers, and 6 community family physicians and conventional content analysis were used to explore social support perspectives at different dementia stages. A total of 470 PWDs were divided into mild $(n=224)$, moderate $(n=190)$, and severe $(n=56)$ groups. Demographic, physical, and psychological factors related to PSS were examined by the group using multiple regression analysis. The group-based characteristics were entered into three prediction models.

Results: In the qualitative study, three themes of social support were identified: two viewpoints refer to social support; different needs and preferences in each stage; non-personalized support services. Quantitatively, the mild group scored lowest in perceived social support, while the severe group scored highest $\left(\chi^{2}=64.70, \mathrm{P}<0.001\right)$. The mild group PSS was predicted by depression $(\beta=-0.07, \mathrm{P}=0.04)$, cognitive capacity $(\beta=-0.18, \mathrm{P}<0.001)$, and instrumental ability $(\beta=-0.78, \mathrm{P}<0.001)$, which differed from the moderate and severe groups.

Conclusion: This study provided comprehensive insight into PSS from PWDs' perspective at different stages of the disease. Results indicated the need for a stratified care approach and direction for further research on intervention.

Keywords: dementia, illness stages, perceived social support, psychosocial status

\section{Introduction}

Worldwide, over 47 million people currently living with dementia, 96\% of whom live at home. ${ }^{1}$ Notably, China ranks first in the number of patients with dementia (PWDs), accounting for $40 \%$ in the Asia-Pacific region and 25\% globally. ${ }^{2}$ PWDs are affected by irreversible and progressive cognitive deterioration, which not only affects their ability to perform daily activities, causes distress, and increases financial burdens, but also places a substantial demand on the social support system. ${ }^{3}$ In 2017, the World Health Organization established social support as a focal item in its Global Action Plan as a public-health response to dementia and further appealed that PWDs receive better benefits. ${ }^{4}$ Recent studies have also demonstrated that adequate social support is strongly associated with both 
psychosocial and general wellbeing among dementia patients. $^{5,6}$ However, few have directly investigated whether effective social support interventions are applied in China.

Several studies have concluded that social support can be subdivided into two main components: structural support and functional support (also referred to as perceived support). ${ }^{7,8}$ Perceived social support is most reliably associated with psychosocial and cognitive function. In this context, PWDs typically living with decreased psychosocial status, which leads to apathy, depression, and anxiety. $^{9-11}$ The perceived social support framework further outlines the characteristics of patient health needs according to four dimensions - information, esteem, social companionship, and instrumental support ${ }^{12,13}$-all of which can help patients better cope with stress and the impact of the disease's physiological processes. ${ }^{14}$ Based on research by Cohen and Wills, ${ }^{12}$ the Interpersonal Support Evaluation List (ISEL) is a useful measure of perceived social support corresponding to the four domains of patient health needs and identifies unmet needs among people with chronic diseases. ${ }^{15-17}$ The ISEL successfully compared levels of perceived social support among people with and without dementia in the United States. ${ }^{18}$ Despite an increasing body of research evaluating social support to provide more effective PWDS interventions, ${ }^{19,20}$ there is limited awareness of this issue in Chinese society. ${ }^{21}$ Therefore, we proposed that the ISEL would aid Chinese health providers, allowing them to more efficiently allocate resources among PWDs.

Previous research has shown that western Chinese care providers often do not implement the types and amounts of support required by $\mathrm{PWDs}^{22}$ regardless of stage and type. $^{23}$ Unfortunately, elderly persons with chronic diseases are often provided with standardized support systems, which may not be properly tailored to their specific conditions. $^{24}$ Further, few studies on home-based social support have focused on dementia patients. This poses an important question: does the "one-size-fits-all" approach meet the needs of PWDs and their family members throughout the disease duration? Previous studies have indicated that patients' perceived social support changes as their diseases progress. ${ }^{25,26}$ Consequently, several predictors may also lead to different perceptions, including age ${ }^{27}$ income, ${ }^{28}$ changing healthcare climates, negative effects, ${ }^{29}$ patient service preferences. ${ }^{30}$ While many predictors have thus been reported, most data were retrieved through clinician and caregiver measurements rather than patient self-reporting. Notably, previous studies have shown that PWDs, including those in the late stages of dementia (MMSE score $\geq 4$ ), can share and exchange ideas, needs, and preferences in meaningful ways and respond to questionnaire investigations, ${ }^{31}$ providing interaction more likely to improve distress. Regardless, the "one-size-fitsall" approach does not address the specific needs of dementia patients. We do not currently know how perceived social support differs throughout the dementia stages or what predictors are associated with specific areas of patient concern.

The perceptions and predictors of social support are also influenced by PWD's and family's culture, health care systems, and insurance. ${ }^{32}$ For example, dementia is not included in the government-subsidized community health service (CHS) package (eg, hypertension and diabetes), and currently, there is few public health care program specifically for dementia in China. ${ }^{33}$ For dementia family, extra resources are still belonging to paid services. Moreover, lack of professionals to engage in dementiaspecific caring (eg, occupational therapist) is a major barrier to achieve dementia management in CHS in China. ${ }^{34}$ This study conducted both qualitative and quantitative analyses to examine stage-related differences in perceived social support among dementia patients by testing two hypotheses: (1) there are stage-related differences in perceived social support among PWDs' perspectives; and (2) there are stage-related predictors of perceived social support among PWDs.

To the best of our knowledge, this study is the first analysis of stage-related differences in perceived social support among dementia patients in China. We, therefore, expected that qualitative interviews were performed to help identify whether any differences, based on stage, exist among PWDs in relation to PSS and what reasons do PWDs experiences of differentiated PSS. Further, a quantitative study was conducted to determine can these predictors explained such stage-related differences in PSS.

\section{Materials and Methods \\ Design}

We conducted qualitative and quantitative research among PWDs, their family carers, and community family physicians from nine districts in Chongqing City. Family carers were contacted first by official accounts on WeChat, posters, mailings, and word of mouth to explain the project and determine interest, and participants were recruited 
between December 2017 and June 2018. Participants were categorized by phases: (1) acquiring research permission from participating institutions (2) conducting semistructured interviews with PWDs at different stages of the disease (12 total), their family carers (12 total), and 6 community family physicians that collected data on social support perspectives and any influencing factors; and (3) distributing questionnaires to 470 PWDs (see the Participant Flow Chart in Figure 1) to determine stagebased (mild, moderate, and severe) differences and predictors. This study was initially approved by the Ethics Committee of the First Affiliated Hospital of Chongqing Medical University (Approved No. 2018-084), which is following the Declaration of Helsinki, and registered with the Chinese Clinical Trial Registry (No. ChiCTR1800019678). All community nurses ( $n=12)$, community family physicians $(n=5)$, and research team members $(n=8)$ were trained and familiarized with the study protocol and measurements prior to recruitment, questionnaire distribution, data collection, and population screening. Those researchers participated in assessments and received 2-week related-training by the psychiatrist, occupational therapist, and geriatric nurse who staffed in a hospital. The study analysis was only conducted by the program statistician (sixth author), who did not participate in such data collection and population screening.

\section{Participants}

Inclusion criteria included: (1) age 65 or older; (2) dementia diagnosis by a neurologist based on the International Classification of Disease, Tenth Revision (ICD-10) or a Mini-Mental State Examination (MMSE) score $\leq 24$; (3) spoke Mandarin (Sichuan dialect) as their primary language; (4) were community-dwelling (day-care center or at home); (5) not bedridden; (6) had family caregiver, or had a contact at least 4 days or 7 hours per week. Family carers and community family physicians were included if they had at least one-year experience for caring PWDs. All participants were informed about the voluntary nature of this study and that they could withdraw at any time; each participant provided written informed consent to participate.

Exclusion criteria included: (1) an MMSE score $<7 ;^{35}$ (2) hearing was inadequate for conversation; (3) vision inadequate to read text written in $22 \mathrm{pt}$. font; (4) unable to complete the ISEL scale. Caregivers who were inability to understand Mandarin (Sichuan dialect) or had mental health problems and those who were not willing to participate were also excluded from this study.
772 participants recruitment in community between December, 2017 and June, 2018

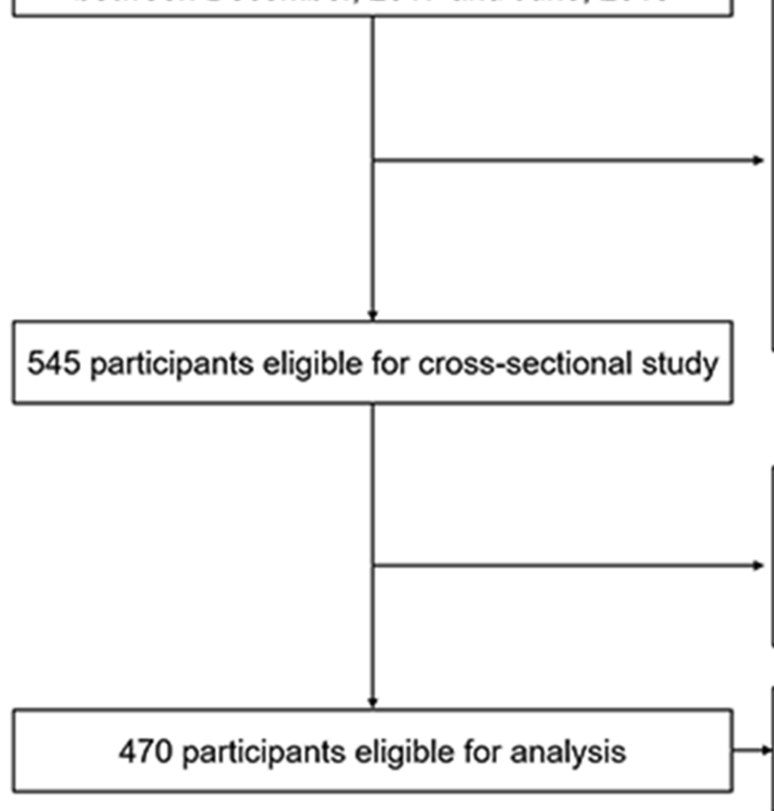

\section{7 did not meet eligibility criteria:}

26 age $<65$

79 MMSE score $>24$

37 MMSE score <7

15 who were bedridden

18 caregiver not available

16 hearing was inadequate for conversational

11 had inadequate vision to read text written in $22 \mathrm{pt}$. font 25 no written informed consent

71 who were excluded:

21 who had inadequate ability to complete ISEL scale 31 missing data

19 withdrew with no reasons

224 mild dementia 190 moderate dementia 56 severe dementia

Figure I Flow chart of participants.

Abbreviations: MMSE, Mini-Mental State Examination; ISEL-I2, Interpersonal Support Evaluation List-I2. 


\section{Sampling}

For the qualitative component, participants were enrolled through purposive sampling at the Daxigou Community Health Center and the Shangqingsi Community Health Center (PWDs' MMSE score range: 12-22). A total of 33 participants were contacted by telephone and the study was explained in detail by the first author. Thirty participants agreed to take part in the interviews (Table 1). Two PWDs (MMSE=13, MMSE=16) refused to complete the interview, citing personal reasons; one interview was paused when the PWDs (MMSE $=20$ ) became emotionally unstable.

For the quantitative component, a total of 474 PWDs were recruited through convenience sampling from nine community health centers (Daxigou, Shangqingsi, Xiejiawan, Shapingba, Lianglukou, Shiqiaopu, Huaxinjie, Lianglu, and Longshan; Figure 1). A total of 772 PWDs were contacted by the community health workers to screen for eligibility; 545 were eligible and 227 did not meet eligibility criteria because of: age $<65 \quad(n=26)$, MMSE score $>24 \quad(n=79)$, MMSE score $<7 \quad(n=37)$, bedridden

Table I Participant Characteristics in Semi-Structure Interview $(n=30)$

\begin{tabular}{|c|c|c|c|}
\hline & $\begin{array}{l}\text { Patient } \\
(n=12)\end{array}$ & $\begin{array}{l}\text { Family } \\
\text { Caregiver } \\
(n=12)\end{array}$ & $\begin{array}{l}\text { Community } \\
\text { Family } \\
\text { Physician } \\
(n=6)\end{array}$ \\
\hline Female (\%) & $6(50)$ & $8(66.7)$ & $4(66.7)$ \\
\hline $\begin{array}{l}\text { Age }(\%) \\
<70 \\
70 \sim \\
>80\end{array}$ & $\begin{array}{l}2(16.7) \\
6(50.0) \\
4(33.3)\end{array}$ & $\begin{array}{l}5(41.7) \\
6(50.0) \\
I(8.3)\end{array}$ & $6(100)$ \\
\hline $\begin{array}{l}\text { Education (\%) } \\
\text { Illiteracy/Primary school } \\
\text { Middle school } \\
\text { High school and above all }\end{array}$ & $\begin{array}{l}6(50) \\
3(25) \\
3(25)\end{array}$ & $\begin{array}{l}7(58.3) \\
3(25) \\
2(16.7)\end{array}$ & $6(100)$ \\
\hline $\begin{array}{l}\text { Socioeconomic Status (\%), } \\
\text { cny/month } \\
<1000 \\
1000 \sim \\
>2000\end{array}$ & $\begin{array}{l}1(8.3) \\
3(25) \\
8(66.7)\end{array}$ & & \\
\hline $\begin{array}{l}\text { CDR (\%) } \\
\text { Mild (MMSE range: 20-22) } \\
\text { Moderate (MMSE range: } \\
\text { 12-19) } \\
\text { Severe }\end{array}$ & $\begin{array}{l}7(58.3) \\
5(41.7)\end{array}$ & $\begin{array}{l}5(41.7) \\
4(33.3) \\
3(25.0)\end{array}$ & \\
\hline Caregiver type (\%), unpaid & & $7(58.3)$ & \\
\hline
\end{tabular}

Abbreviations: MMSE, Mini-Mental State Examination; CDR, Clinical Dementia Rating Scale. $(\mathrm{n}=15)$, caregiver not available $(\mathrm{n}=18)$, hearing inadequate for conversation $(\mathrm{n}=16)$, impaired vision prevented reading $22 \mathrm{pt}$. typeface $(\mathrm{n}=11)$, and did not provide informed consent $(\mathrm{n}=25)$. The final analysis included 470 participants; 71 PWDs were excluded for: unable to complete the ISEL ( $n=21)$, missing data $(n=31)$, or withdrew without providing a reason $(\mathrm{n}=19)$.

\section{Assessment Instruments Qualitative Data}

The semi-structured interview schedule comprised openended questions designed to elicit participants' perceptions, experiences, and views of social support. Patients were asked: what supports have you received so far (how do you feel), what you experience in daily life, and what else do you need. Family caregivers and community family physicians were asked: what is social support, what supports do you provide for PWDs; what difficulties do you have taking care of her/him (how do you feel); and what things influence social support. Interviews were independently conducted and recorded in the individual homes or daycare centers and lasted between 15 and 46 minutes. All recordings were transcribed for analysis. Field-notes were made to record observations and reflections of the interviews. The interview was paused and comfort provided when the interviewee became emotionally unstable.

\section{Quantitative Data}

Information was collected based on Cohen's social support theory. ${ }^{12}$ In accordance with previous studies and qualitative findings, ${ }^{36}$ PSS related factors, such as daily activities, cognitive function, psychosocial status, and demographics (ie, physical health status and caregiver type), were collected to explore stage-based differences in perceived social support and any predictive variables. Outcome measures included six questionnaires with well-established validity and reliability, as described in Table 2. The Neuropsychiatric Inventory (NPI; including nighttime behaviors, irritability, apathy, depression, and motor disturbance), Mini-Mental State Examination (MMSE), Interpersonal Support Evaluation List-12 (ISEL-12), Activities of Daily Living (ADL), and Functional Assessment Questionnaire (FAQ) were administered to all PWDs. All questionnaire items were completed through face-to-face interviews, which conducted by trained research staff. Demographic information was collected from an information questionnaire and community healthcare center records. All questionnaires were self-report 
Table 2 Study Measures, Descriptions, and Reliability

\begin{tabular}{|c|c|c|c|c|}
\hline $\begin{array}{l}\text { Construct } \\
\text { Scale }\end{array}$ & $\begin{array}{l}\text { Items } \\
\text { in Scale }\end{array}$ & Cronbach's $\alpha$ & $\begin{array}{l}\text { Scale } \\
\text { Score } \\
\text { Range }\end{array}$ & Description \\
\hline \multicolumn{5}{|c|}{ Instruments Completed by Neurologist } \\
\hline $\mathrm{CDR}^{52}$ & 6 & 0.91 & I, 2, or 3 & $\begin{array}{l}\text { The Clinical Dementia Rating scale (CDR) uses a semi-structured interview with both the patient and } \\
\text { a reliable informant to assess performance of cognitive functions in six domains: memory, orientation, } \\
\text { judgment and problem solving, community affairs, home and hobbies, and personal care. Impairment is } \\
\text { defined only when caused by cognitive loss rather than by physical disability or other non-cognitive factors. } \\
\text { The scale helps neurologists rate the severity of dementia and related disorders on a 5-point scale from I } \\
\text { (mild) to } 3 \text { (severe) based on clinical interviews with an informant and the person with dementia. Areas } \\
\text { assessed include memory, orientation, judgment, problem solving, community affairs, and home and hobbies. }\end{array}$ \\
\hline $\mathrm{NPI}^{53}$ & 12 & 0.84 & $\begin{array}{l}\text { Each item: } \\
0-12\end{array}$ & $\begin{array}{l}\text { The Neuropsychiatric Inventory (NPI) is designed to be a self-administered questionnaire completed by } \\
\text { informants about patients for whom they care. Each of the } 12 \text { items is rated on a 4-point frequency scale } \\
\text { and a 3-point severity scale. Each of the } 12 \text { NPI domains contains an item that reflects key symptoms of } \\
\text { that domain. Initial responses to each domain item are "Yes" (present) or "No" (absent). After "No," } \\
\text { responses, the informant goes to the next question; after "Yes" responses, the informant rates both } \\
\text { symptom severity within the last month on a 3-point scale and the associated impact on the caregiver of } \\
\text { the symptom manifestations (ie, Caregiver Distress) using a } 5 \text {-point scale. The NPI provides symptom } \\
\text { severity and distress ratings for each symptom reported, and total severity and distress scores reflecting } \\
\text { the sum of individual domain scores. Five sub-items with high incidence in Chinese communities were } \\
\text { added for this study: nighttime behaviors, irritability, apathy, depression, and motor disturbance. }{ }^{39} \text { (For } \\
\text { example, apathy: Does the patient seem less interested in his/her usual activities or in the activities and } \\
\text { plans of others? Agitation: Does the patient resist help from others at times, or become hard to handle?) }\end{array}$ \\
\hline $\mathrm{MMSE}^{54}$ & 11 & 0.85 & $0-30$ & $\begin{array}{l}\text { The Mini-Mental State Examination (MMSE) is a widely used standardized cognitive screening scale } \\
\text { administered by trained clinicians and designed to detect cognitive impairment. It assesses cognitive } \\
\text { domains, including: orientation to time and place, registration, attention/calculation, recall, language } \\
\text { (including naming, repetition, comprehension, reading, and writing), and copying. A score of } 24 \text { or below } \\
\text { suggests cognitive impairment. For example, "take the paper in your right hand, fold it in half, and put it } \\
\text { on the floor." (The examiner gives the patient a piece of blank paper.) }\end{array}$ \\
\hline \multicolumn{5}{|c|}{ Instruments Completed by PWDs } \\
\hline ISEL-1 $2^{55}$ & 12 & 0.76 & $0-36$ & $\begin{array}{l}\text { The Interpersonal Support Evaluation List-I2 (ISEL-I2) measures perceived social support. Each item is scored } \\
\text { on a 4-point scale ranging from "definitely false" to "definitely true." It has three subscales: perceived availability } \\
\text { of appraisal (advice or guidance), belonging (empathy, acceptance, concern), and tangible social support (help or } \\
\text { assistance, such as material or financial aid). The ISEL measures the perceived availability of social resources in } \\
\text { four categories: tangible support (the availability of material aid such as help with transportation, child care, and } \\
\text { finances), for example, "if I got stranded I0 miles out of town, there is someone I could call to come get me"; } \\
\text { appraisal support (the availability of someone to talk to about one's problems), for example "I feel that there is } \\
\text { no one with whom I can share my most private worries and fears" (reverse scored); and belonging support (the } \\
\text { availability of people to do things with), for example "I don't often get invited to do things with others" (reverse } \\
\text { scored) and "there are several different people with whom I enjoy entertainment time." Higher scores denote } \\
\text { better perceived social support. The following are examples of answers given to stimulus questions such as "If } \\
\text { you wanted to go on a trip to the country or mountains, would you have a hard time finding someone to go with } \\
\text { you?". An PWDs with an MMSE score of } 7 \text { stated, "I doubt if I'd even go on a trip." But, two PWDs (MMSE=8 } \\
\text { and I0, respectively) had incorrect responses: eg, "is there someone would look after your pets when you left?" } \\
\text { responded "yeah, I'm a journalist." The ISEL was translated into Chinese by this study's researchers and } \\
\text { subsequently received a Cronbach's alpha score of } 0.76 \text {. }\end{array}$ \\
\hline \multicolumn{5}{|c|}{ Instruments Completed by Community Nurse } \\
\hline $\mathrm{ADL}^{56}$ & 10 & 0.9 & $0-100$ & $\begin{array}{l}\text { Activities of daily living (ADL) were assessed using the Barthel Index (BI), which assesses walking, feeding, } \\
\text { dressing and grooming, toileting, bathing, and transferring. Higher scores indicate better self-care abilities. It is } \\
\text { administered by a community nurse and includes items such as: "can your loved-one feed themselves?" please } \\
\text { note that this ADL refers to feeding themselves specifically; if your loved-one cannot prepare meals but can } \\
\text { still feed themselves then they pass this ADL. Common eating complications are a physical inability to } \\
\text { swallow, difficulty chewing food, and trouble moving food from the plate to the mouth. }\end{array}$ \\
\hline
\end{tabular}


Table 2 (Continued).

\begin{tabular}{|l|l|l|l|l|}
\hline $\begin{array}{l}\text { Construct } \\
\text { Scale }\end{array}$ & $\begin{array}{l}\text { Items } \\
\text { in Scale }\end{array}$ & Cronbach's $\alpha$ & $\begin{array}{l}\text { Scale } \\
\text { Score } \\
\text { Range }\end{array}$ & Description \\
\hline FAQ $^{56}$ & 10 & 0.9 & $0-20$ & $\begin{array}{l}\text { The Functional Assessment Questionnaire (FAQ) comprises I0 items that assess performance levels, } \\
\text { including: (a) writing checks, paying bills, or balancing a checkbook; (b) assembling tax records, business } \\
\text { affairs, or other papers; (c) shopping alone for clothes, household necessities, or groceries; (d) playing } \\
\text { a game of skill such as bridge or chess or working on a hobby; (e) heating water, making a cup of coffee, } \\
\text { turning off the stove; (f) preparing a balanced meal; (g) keeping track of current events; (h) paying } \\
\text { attention to and understanding a TV program, book, or magazine; (i) remembering appointments, family } \\
\text { occasions, holidays, medications; (j) traveling out of the neighborhood, driving, or arranging to take public } \\
\text { transportation. Scores reflect dependence or independence (eg, dependent = 2, requires assistance or } \\
\text { has difficulty but does by self = I, normal = 0. For example, personal care: cutting your toenails, getting } \\
\text { up from a low seat, and climbing stairs). }\end{array}$ \\
\hline
\end{tabular}

except the NPI. We adapted the questionnaires to improve data collection efficiency, such as increasing the font size, using graphics instead of text, using dichotomous answers (yes/no), and providing scenario simulation.

\section{Analysis}

All qualitative data were used as a conventional approach to content analysis. Information of all samples (PWDs and carers) was summarized and transcribed using Microsoft Word. $^{37}$ The iterative analysis process included: (1) First and second authors jointly read each transcript. (2) Highlighted the words or phrases which described the meaning and feelings of social support. (3) These keywords or phrases were formed into codes. (4) Coresearchers checked all the data in the specific codes. (5) Added new codes when researchers encountered data that did not fit into existing code. Information saturation was achieved when no new themes emerged. (6) Discussed codes with co-researchers and used to supplement and refine the coding scheme. (7) Classified codes and grouped into descriptive categories.

Quantitative data were analyzed with IBM SPSS Statistics, version 23.0 (IBM Corporation, Armonk, NY, USA). Patients were grouped into three categories based on their CDR scores (ie, mild: CDR 1, moderate: CDR 2, and severe: CDR 3 and MMSE $\geq 7$ ). The Pearson's $\chi 2$ test was then used to compare stage-based categorical variables; analysis of variance and Kruskal-Wallis $H$-tests were performed to compare the mean values of the continuous variables. Bonferroni post hoc adjustments were used. Statistical significance was set at $P<0.05$ for all analyses.

Multiple linear regression analyses were then used to determine the predictors of perceived social support for each group. All variables were forced into the model for simultaneous control, including age, sex, education, socioeconomic status, physical health status, caregiver type, and the PSS, ADL, FAQ, NPI (nighttime behaviors, irritability, apathy, depression, and motor disturbance), and MMSE scores. The multivariate linear regression analysis model fit was tested by model-residual and normal-probability graphs. Weighted multiple regression analysis was used in the presence of heteroscedasticity.

\section{Results}

\section{Qualitative Findings}

\section{Two Viewpoints in Social Support}

Both PWDs and carers (Table 1) described social support as receiving assistance to improve living conditions. However, an interpretation of social support revealed two separate aspects of their concern. A mild patient [P02 (MMSE score=20)] said, “ ... make easier [life] but now, I am afraid of going out ... I want her [wife] to go out with me ..." ; a moderate patient [P03 (MMSE score=12)] said, “... she [wife] is here ... I feel safety ...."; a community family physician [CC04] stated, "I think, it means the amount of supports would be available if it was need[ed] ..."; and a family caregiver [FC02] said, "I almost spend all my time .. . tired ... [sigh] ... I have to take charge of all things ... eating, drinking, and excretion" [patient at severe stage]. "The more time and efforts you spend on the patient, the better life he (she) gets", another family caregiver [FC04] stated.

As indicated, patients and caregivers all acknowledged the positive impact of social support. However, PWDs were more focused on the "functional features" of social support (eg, they can perceive assistance and accompany which provided from caregivers), while carers tended to 
focus on the "structural features" (eg, time-consuming care and type of social support).

\section{Different Needs and Preferences in Each Stage}

Lower levels of respect and restricted social activities were described in mild-stage patients. As shared by a mild patient [P07 (MMSE=19)], “ ... shame on me [husband], he sometimes likes to talk about it with others [dementia]." Another mild patient [P04 (MMSE=18)] stated,

... I'm just older and slower ... actually ... being able to care for myself ... they [husband and sons] insist [on] me staying at home and restrict other independent behaviors for safety ... it's not as bad as what they said [frown] ... they had me as an imbecile.

"perceived Independent and respect" described their perceptions about what reflecting great experiences for social support. Most mild-group patients reported negative emotion, “ ... sometimes I feel boring ... have been sitting at day-care center watching television ... no talks to others ... what's happening to me [frown]?" as shared by another patient [P05 (MMSE score=21)]. "emotional input" described their perceptions reflecting what support is required for them.

For advanced PWDs, more stable emotional supports were demonstrated. A higher need for "accompany and assistance" was reflected in moderate patients [P01 (MMSE=14)], “ . . okay ... she [wife] is here [at home] . ..” That perspective of acceptance was shared by another patient [P02 (MMSE=13)]. Patients with moderate dementia worried about uncontrollable behavior, which was reported as the most stressful matter. A moderate patient [P04 (MMSE=15)] stated, "I always awoke [at midnight] . . . [gloomy], she [daughter] always consoled me ....”

\section{Non-Personalized Support Services}

Although caregivers lived with greater mental and physical pressure when patients were sick, they were still willing to maintain their roles, especially family members. In that case, most of them reported that the actual needs of PWDs were "hardly understanding". An unpaid caregiver whose husband had severe dementia [FC02] stated,

Although my burden is pretty heavy [sigh], as his wife, it's my obligation to care for him ... I feel so tired ... it's hardly [the type of] communications as it was previously ... I can guess his emotion if he gives me some words or expressions.

Another unpaid carer [FC05] reported,
My mom [with mild dementia] became more and more reluctant to talk when she knew her situation ... suddenly showed to be unhappy or upsetting ... I don't know, what good coping strategies can take me to escape from this problem....

Compared to the unpaid caregiver, less understanding of PWDs was reported by paid caregivers. One paid caregiver [FC10] said, " ... It's hard for me ... like understanding their [with severe dementia] emotional change." For paid caregivers and family physician, "usually care" described their perceptions of supports in caring. Patient perspectives were rarely considered when making decisions during routine community-conducted home visits. One community family physician [CC03] stated,

... [we] provide more concerns with non-differential management of chronic diseases for patients ... and indeed, it is hard to provide person-centered care ... cannot fully understand everyone's needs, especially PWDs ....

Another community family physician [CC04] said, ... we provide visits services for them [PWDs], which focused on their basic needs and symptoms management .. .... no, no occupational therapy and counseling ... like other chronic disease management ... the regulation visits [service times] are twice a week.

\section{Quantitative Findings}

Overall, the refusal/non-response rate was $39.1 \%$. The 470 PWDs enrolled in the quantitative study had a mean age of 78.3 years (SD 7.3). The mild group included 224 participants $(47.7 \%) ; 190(40.4 \%)$ were in the moderate-group; and $56(11.9 \%)$ were in the severe group. Demographic data are presented in Table 3. There were no major between-group differences in sex, age, education, socioeconomic status, physical health status, or caregiver type.

Significant within-group ISEL-12 score differences are shown in Figure 2. Notably, ISEL-12 scores (mild dementia group $=(21.25 \pm 3.13)$, moderate dementia group $=(22.49$ $\pm 5.65)$, and severe dementia group $=(26.98 \pm 3.08))$ increased with disease severity $\left(\chi^{2}=183.16, P<0.001\right)$. There were also significant within-group differences for the MMSE (range: 7-24), ADL, FAQ, and NPI (sleep, irritability, depression, and behavior) scores, whereas no significant difference emerged for apathy. Based on this finding, we expect that these different factors represent distinct stages of PSS perception.

The multiple regression model (Table 4) for the mild group explained $79.0 \%$ of the total variance of ISEL-12 scores, 
Table 3 Demographic Characteristics $(n=470)$

\begin{tabular}{|c|c|c|c|c|c|}
\hline & $\begin{array}{l}\text { Total } \\
(n=470)\end{array}$ & $\begin{array}{l}\text { Mild Dementia } \\
(n=224)\end{array}$ & $\begin{array}{l}\text { Moderate Dementia } \\
(n=190)\end{array}$ & $\begin{array}{l}\text { Severe Dementia } \\
(n=56)\end{array}$ & p-value \\
\hline \multicolumn{6}{|l|}{$\operatorname{Sex}(\%)$} \\
\hline Female & $247(52.6)$ & II4 (50.9) & $104(54.7)$ & $29(51.8)$ & 0.73 \\
\hline Male & $223(47.4)$ & $110(49.1)$ & $86(45.3)$ & $27(48.2)$ & \\
\hline Age, years, mean (SD) & $78.27(7.31)$ & $77.72(6.86)$ & $79.85(7.85)$ & $78.46(7.16)$ & 0.29 \\
\hline \multicolumn{6}{|l|}{ Education (\%) } \\
\hline Illiteracy/Primary school & $187(39.8)$ & $89(39.7)$ & $78(4 I . I)$ & $20(35.7)$ & 0.75 \\
\hline Middle school & $120(25.5)$ & $62(27.7)$ & $43(22.6)$ & $15(26.8)$ & \\
\hline High school and above all & $163(34.7)$ & $73(32.6)$ & $69(36.3)$ & $21(37.5)$ & \\
\hline \multicolumn{6}{|l|}{$\begin{array}{l}\text { Socioeconomic Status (\%), cnyl } \\
\text { month }\end{array}$} \\
\hline$<1000$ & $136(28.9)$ & $63(28.1)$ & $57(30.0)$ & $16(28.6)$ & 0.96 \\
\hline $1000 \sim$ & $168(35.7)$ & $84(37.5)$ & $65(34.2)$ & $19(33.9)$ & \\
\hline$>2000$ & $166(35.3)$ & $77(34.4)$ & $68(35.8)$ & $21(37.5)$ & \\
\hline Physical health status, mean (SD) & $2.1(0.77)$ & $2.13(0.75)$ & $2.04(0.76)$ & $2.21(0.87)$ & 0.25 \\
\hline \multicolumn{6}{|l|}{ Caregiver Type (\%) } \\
\hline Unpaid & $284(60.4)$ & $136(60.7)$ & $112(58.9)$ & $36(64.3)$ & 0.77 \\
\hline Paid & $186(39.6)$ & $88(39.3)$ & $78(4 I . I)$ & $20(35.7)$ & \\
\hline
\end{tabular}

Abbreviation: SD, standard deviation.

which was predicted by depression, FAQ, MMSE scores, and age. Better cognitive function, more limited instrumental daily activities, and depression were associated with lower PSS. Compared with advanced dementia patients, those with better cognitive function were more aware of the related psychosocial effects. In the moderate group, predictors included education, behavior problems, ADL, FAQ, and MMSE scores, which explained $75.1 \%$ of the variance in the ISEL-12 scores. Lower PSS was predicted by lower education, high levels of behavioral problems, daily activities, and better cognitive capacity. In the severe group, $64.4 \%$ of the total variance in the ISEL-12 scores was explained by caregiver type and ADL. Lower PSS was predicted by paid caregivers and better basic daily living abilities. It means that in advanced dementia, awareness deficits tend to be a protective factor of PWDs with reduced cognitive capacity, which might contribute to their improved subjective experience.

\section{Discussion}

This was the first study to explore how PSS differed among PWDs at different disease stages in China and to identify the factors associated with these differences. Qualitative data analyses suggested that a divergent interpretation of social support and limited psychosocial support mainly contributed to low PSS reported by patients with mild dementia. There were two main quantitative findings: (1) patients with mild dementia had worse PSS than patients at more advanced stages; and (2) PSS predictors differed by group (mild, moderate, and severe). These findings validated our two hypotheses, thus adding to the social support literature by verifying different levels of perceived social support at different stages of the disease. ${ }^{25}$

As noted, BPSD (ie, agitation, depression, apathy, aggression, sleep problems, wandering, and a variety of socially inappropriate behaviors) episodically fluctuate throughout the dementia stages. ${ }^{38}$ This contributes to perceived social support impairment. ${ }^{9}$ This study found certain BPSD factors (ie, depression and motor disturbance) were significantly associated with relatively lower PSS in mild and moderate patients. These results may explain previous findings reporting more episodes of BPSD in mild and moderate patients than advanced patients. ${ }^{39}$ Fluctuating psychosocial symptoms may be caused by impaired left-hemisphere emotional regulators, ${ }^{40}$ while in advanced-stage patients, this may weaken functioning while suppressing negative emotions, thus making individuals more inclined toward positive effects. ${ }^{41,42}$ The qualitative results showed that carers did not pay attention to or deal with patients' negative emotions; this may result in lower perceived social support, which was reported by 


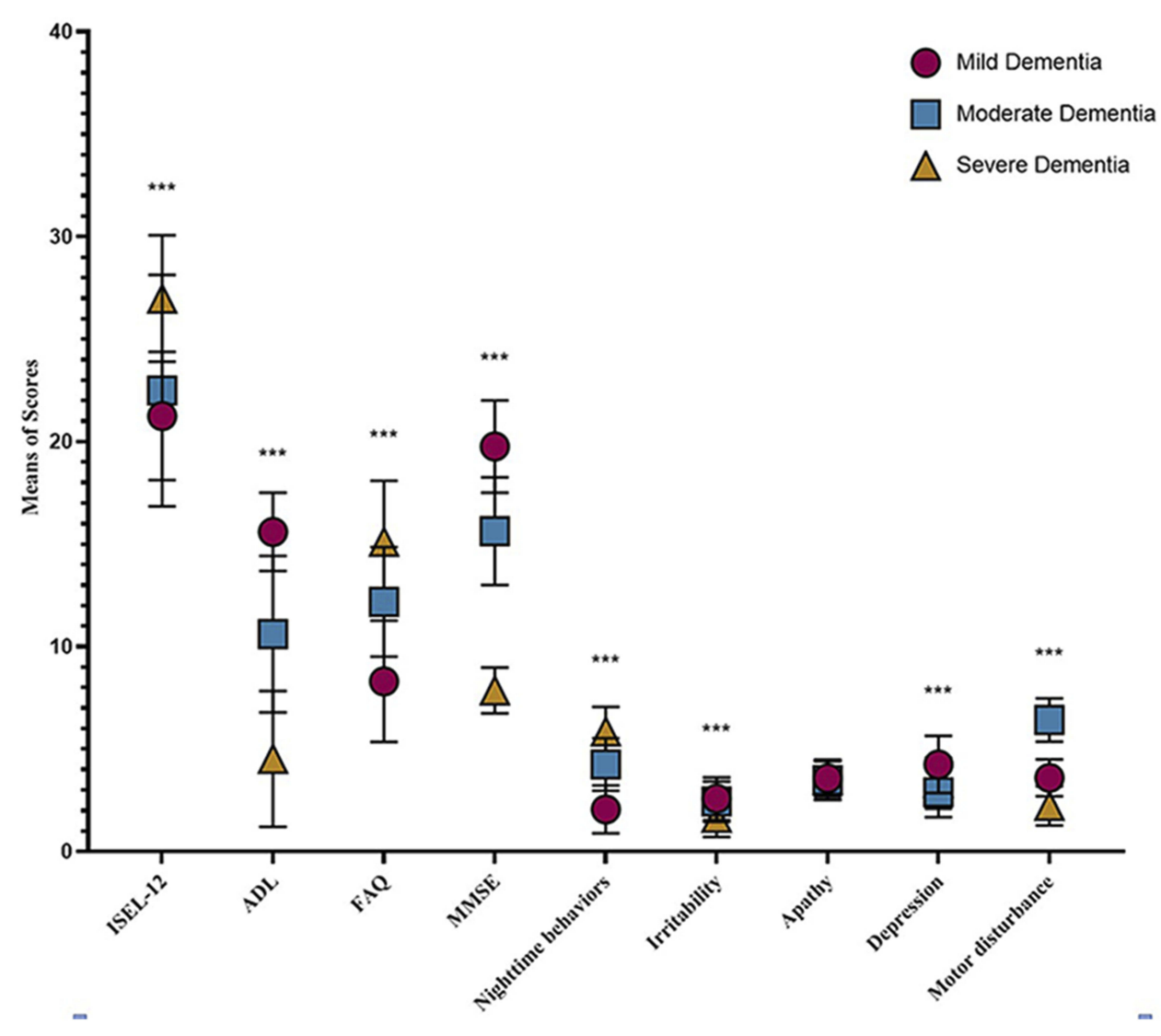

Figure 2 Scores of mean and SD in ISEL-I2, ADL, FAQ, NPI, and MMSE among the AD with mild, moderate, and severe stage.

Notes: $* * *$ Significant difference among the three groups $(P \leq 0.00 \mathrm{I})$.

Abbreviations: ISEL-12, Interpersonal Support Evaluation List-I2; ADL, activities of daily life (the 100 points were converted to 20 points); FAQ, Functional Assessment Questionnaire; NPI, Neuropsychological Inventory (nighttime behaviors, irritability, apathy, depression, and motor disturbance); MMSE, Mini-Mental State Examination.

mild dementia patients more often than by those in severe stages.

Interestingly, better cognitive function was another predictor of worse PSS in mild-dementia patients. The narrative descriptions obtained from mild-group patients and their carers provided additional insight into the mechanism underlying lower PSS among mild dementia patients. Compared with advanced dementia patients, those with better cognitive function were more aware of the related psychosocial effects. Most believed that dementia threatened the meaning of life, their individual identities, and their overall wellbeing. Consequently, these patients tended to avoid dementia-related information (eg, showing impatience or shame when discussing diseaserelated topics). This finding was consistent with a previous study by Cheston et al, in which mild dementia patients had poor recall of dementia-related information when it referred to them as opposed to other persons. ${ }^{43}$ Traditional Chinese values emphasize moral excellence and self-cultivation of harmony within the self, family, and society, however, dementia symptoms such as BPSD have broken this harmony. Most families of people with dementia refused to disclose the condition to avoid stigma and it marked respect lacking in society. ${ }^{21}$ Therefore, psychosocial processes related to threat awareness may result in lower PSS levels in those with mild dementia. Conversely, in patients with advanced dementia, awareness of deficits tends to decline with reduced cognitive capacity, which might contribute to their improved subjective assessment. ${ }^{35}$

Notably, we found that PWDs and their carers had different perspectives on social support. For instance, mild dementia patients were more positive about their own social abilities than were their family members. However, we were unable to determine whether these differences result from patient underreporting and/or carer overreporting, but as a patient said,

... I'm just older and slower ... actually ... being able to care for myself ... they [husband and sons] insist [on] me 
Table 4 Multiple Regression Results for the Perceived Social Support Scores of Dementia by Stage Groups $(n=470)$

\begin{tabular}{|c|c|c|c|c|c|c|}
\hline \multirow[t]{2}{*}{ Variables } & \multicolumn{2}{|c|}{ Mild Dementia $(n=224)$} & \multicolumn{2}{|c|}{ Moderate Dementia $(n=190)^{e}$} & \multicolumn{2}{|c|}{ Severe Dementia $(n=56)$} \\
\hline & Standardised $\beta$ & p value & Standardised $\beta$ & p value & Standardised $\beta$ & p value \\
\hline Sex, Male ${ }^{a}$ & 0.03 & 0.34 & 0.09 & 0.17 & 0.03 & 0.76 \\
\hline Age, years & -0.08 & 0.01 & 0.02 & 0.72 & -0.07 & 0.42 \\
\hline \multicolumn{7}{|l|}{ Education ${ }^{\mathrm{b}}$} \\
\hline Middle school & -0.05 & 0.18 & 0.02 & 0.72 & 0.17 & 0.11 \\
\hline High school and above all & -0.05 & 0.15 & 0.21 & 0.001 & 0.15 & 0.17 \\
\hline \multicolumn{7}{|l|}{ Socioeconomic Status, cny/month ${ }^{c}$} \\
\hline $1000 \sim$ & -0.05 & 0.24 & 0.11 & 0.16 & 0.02 & 0.85 \\
\hline$>2000$ & -0.004 & 0.92 & 0.13 & 0.07 & -0.05 & 0.61 \\
\hline Caregiver Type, unpaid ${ }^{d}$ & -0.04 & 0.28 & 0.11 & 0.05 & -0.20 & 0.02 \\
\hline ADL Scores & -0.01 & 0.96 & -0.50 & $<0.001$ & -0.90 & $<0.001$ \\
\hline \multicolumn{7}{|l|}{ NPI Scores } \\
\hline Sleep & 0.005 & 0.89 & 0.10 & 0.08 & 0.11 & 0.21 \\
\hline Irritability & -0.05 & 0.13 & 0.002 & 0.98 & 0.03 & 0.74 \\
\hline Apathy & -0.04 & 0.21 & -0.04 & 0.49 & -0.09 & 0.32 \\
\hline Depression & -0.07 & 0.04 & 0.01 & 0.87 & -0.06 & 0.47 \\
\hline Behavior & -0.06 & 0.08 & -0.257 & $<0.001$ & -0.02 & 0.82 \\
\hline FAQ Scores & -0.78 & $<0.001$ & -0.260 & $<0.001$ & -0.09 & 0.30 \\
\hline MMSE Scores & -0.18 & $<0.001$ & -0.147 & 0.04 & -0.14 & 0.13 \\
\hline Adjusted $R^{2}$ (model $P$ value) & \multicolumn{2}{|l|}{$0.790(<0.001)$} & \multicolumn{2}{|l|}{$0.75 \mathrm{I}(<0.001)$} & \multicolumn{2}{|l|}{$0.644(<0.001)$} \\
\hline
\end{tabular}

Notes: ${ }^{\text {a}}$ Female; ${ }^{b}$ illiteracy/primary school; ${ }^{\mathrm{c}}<1000$; ${ }^{\mathrm{d}}$ Unpaid; ${ }^{\mathrm{e}}$ weighted by unstandardized residual.

Abbreviations: ADL, activities of daily life; NPI, neuropsychological inventory; FAQ, Functional Assessment Questionnaire; MMSE, Mini-Mental State Examination.

staying at home and restrict other independent behaviors for safety ....

Further, PWDs tended to concentrate on their inner degree of social support in terms of understanding it, while carers typically paid attention to the frequency and size of the support, believing, "The more time and efforts you spend on the patient, the better life he (she) gets." Conflicting perspectives may accentuate patients' negative emotions and make them feel disrespected. These contradictions may also reflect the important roles of negative emotions and perceptive gaps in social support, thus explaining the overall lower perceived social support in mild dementia patients. $^{44}$

In contrast to patients with mild-to-moderate dementia, we found that the "pleasant or gentle response" was most prevalent in the severe group when they were with family caregivers. For example, moderate-stage participants demonstrated a weaker desire for interaction, or "relationship numbness," as general apathy or reluctance developed. When family carers communicated with recipients through vocalizations, bodily contact, and gestures, severe patients frowned less frequently and showed more relaxed expressions compared to those in less severe stages. Our quantitative results indicated that individuals with severe dementia cared for by relatives had better PSS; severe patients were more dependent on their carers because of declines in linguistic competence and daily living activity; and intensive interaction and sense of security occurred more between family members, especially in the context of Chinese culture. $^{45}$ This is based on the previous shared experiences of communication, including eye gaze, emotional expression, and movements. ${ }^{46}$ However, patients' habitual nonverbal attempts might be typically ignored ${ }^{47}$ or judged incomprehensible ${ }^{48}$ by paid carers, who formed relationships with PWDs who already had significant linguistic barriers by the time they met. ${ }^{49}$ Most caregivers lack training and education on management of dementia in China, such as cognitive exercises and rehabilitation, only provide basic care on eating, dressing, and bathing. Additionally, caregiver populations were lacking employment access systems, resulting in 
employee caregivers usually as a nanny. ${ }^{50}$ Therefore, support from a close family member related to all-day basic living care and better emotional sharing, which may result in higher levels of perceived social support from patients in later stages.

\section{Strengths and Limitations}

This study had several strengths, including (1) its examination of a large Chinese community-based cohort, (2) a mixed-methods approach to assess perceived social support across three dementia stages, (3) an original perspective in differentiating perceived social support in terms of dementia progression, and (4) a broad analytical approach to examining lower perceptions of social support among patients with mild dementia. The main criticism that may be levelled at this study is that it included severe dementia patients as participants. In the qualitative study, although severe PWDs were not interviewed directly, we obtained their social support status through limited verbal feedback, observation of expressions and behaviors, and communication with their caregivers; we enrolled PWDs with MMSE $\geq 7$ in the quantitative study, most of whom had the ability to complete questionnaires. ${ }^{51}$ In addition, we did not intensively investigate participant structural support; instead, we assumed that the "size" of their social network would be similar to that of older persons under the Chinese unitary community health care model. Finally, we only examined data from western China. Therefore, our findings may have limited generalizability.

\section{Conclusion}

In China, mild dementia patients experienced the lowest perceived social support. Perceptions and predictors differed according to the relative salience of perceived social support in each stage. Further, the predictors of social support can become "moving targets," with different symptoms appearing at different stages of the disease. This reinforces the importance of performing specific evaluations and interventions that are tailored to patient needs. This study provides guidance for stage-specific clinical practices and those looking to develop community-based, long-term care systems for dementia patients.

\section{Data Sharing Statement}

Individual participant data that underlie the results reported in this article will be shared, after deidentification (text, tables, and figures). Data are available for beginning 9 months and ending 36 months following article publication.
Proposals should be directed to yangb@hospital.cqmu.edu. $\mathrm{cn}$. To gain access, data requestors will need to an agreement. Additionally, no further data will be shared besides what is included in the manuscript.

\section{Acknowledgments}

This work was supported by the Chongqing Science and Technology Commission (Grant nos cstc2017shmsA10001 and cstc2018jscx-mszdX0013). The authors thank the patients and their caregivers. We are also grateful to doctors and nurses in the First Affiliated Hospital of Chongqing Medical University and community health workers for participating in this study.

\section{Disclosure}

The authors report no conflicts of interest in this work.

\section{References}

1. Alzheimer's Disease International. Global estimates of informal care; July 2018. Available from: https://www.alz.co.uk/adi/pdf/globalestimates-of-informal-care.pdf. Accessed 10 August 2019.

2. Song Y, Wang J. Overview of Chinese research on senile dementia in mainland China. Ageing Res Rev. 2010;9:S6-S12. doi:10.1016/j. arr.2010.08.007

3. Harrison KL, Ritchie C, Patel K, et al. Care settings and clinical characteristics of older adults with moderately severe dementia. J Am Geriatr Soc. 2019;67(9):1907-1912. doi:10.1111/jgs.16054

4. Lancet Neurology T; The Lancet Nurology. WHO has a dementia plan, now we need action. Lancet Neurol. 2017;16(8):571. doi:10.1016/S1474-4422(17)30207-7

5. Khondoker M, Rafnsson SB, Morris S, Orrell M, Steptoe A. Positive and negative experiences of social support and risk of dementia in later life: an investigation using the english longitudinal study of ageing. J Alzheimers Dis. 2017;58(1):99-108. doi:10.3233/JAD161160

6. Leung P, Orrell M, Orgeta V. Social support group interventions in people with dementia and mild cognitive impairment: a systematic review of the literature. Int $J$ Geriatr Psychiatry. 2015;30(1):1-9. doi:10.1002/gps.4166

7. Gottlieb BH, Bergen AE. Social support concepts and measures. Psychosom Res. 2010;69(5):511-520. doi:10.1016/j.jpsychores.2009. 10.001

8. Gallo LC, Fortmann AL, McCurley JL, et al. Associations of structural and functional social support with diabetes prevalence in US hispanics/latinos: results from the HCHS/SOL sociocultural ancillary study. J Behav Med. 2015;38:160-170. doi:10.1007/s10865-0149588-z

9. Uchino BN. Understanding the links between social support and physical health: a life-span perspective with emphasis on the separability of perceived and received support. Perspect Psychol Sci. 2009;4(3):236-255. doi:10.1111/j.1745-6924.2009.01122.x

10. Pillemer SC, Holtzer R. The differential relationships of dimensions of perceived social support with cognitive function among older adults. Aging Ment Health. 2016;20:727-735.

11. Steinberg M, Shao H, Zandi P, et al. Point and 5-year period prevalence of neuropsychiatric symptoms in dementia: the Cache County Study. Int $J$ Geriatr Psychiatry. 2008;23(2):170-177. doi:10.1002/gps.1858 
12. Cohen S, Wills TA. Stress, social support, and the buffering hypothesis. Psychol Bull. 1985;98(2):310. doi:10.1037/0033-2909.98.2.310

13. Cohen S, Hoberman HM. Positive events and social supports as buffers of life change stress. J Appl Soc Psychol. 1983;13 (2):99-125. doi:10.1111/j.1559-1816.1983.tb02325.x

14. Uchino BN. Social support and health: a review of physiological processes potentially underlying links to disease outcomes. $J$ Behav Med. 2006;29(4):377-387.

15. Hall RK, Davenport CA, Sims M, et al. Association of functional and structural social support with chronic kidney disease among African Americans: the Jackson Heart Study. BMC Nephrol. 2019;20(1):262. doi:10.1186/s12882-019-1432-9

16. Cohen S, Mermelstein R, Kamarck T, Hoberman HM. Measuring the functional components of social support. In: Sarason IG, Sarason BR, editors. Social Support: Theory, Research and Applications. Dordrecht: Springer; 1985:73-94.

17. Haugland T, Wahl AK, Hofoss D, DeVon HA. Association between general self-efficacy, social support, cancer-related stress and physical health-related quality of life: a path model study in patients with neuroendocrine tumors. Health Qual Life Outcomes. 2016;14(1):11. doi:10.1186/s12955-016-0413-y

18. Ennis SK, Larson EB, Grothaus L, et al. Association of living alone and hospitalization among community-dwelling elders with and without dementia. J Gen Intern Med. 2014;29(11):1451-1459.

19. Black BS, Johnston D, Leoutsakos J, et al. Unmet needs in community-living persons with dementia are common, often non-medical and related to patient and caregiver characteristics. Int Psychogeriatr. 2019;31(11):1643-1654. doi:10.1017/ S1041610218002296

20. Black BS, Johnston D, Rabins PV, et al. Unmet needs of community-residing persons with dementia and their informal caregivers: findings from the maximizing independence at home study. J Am Geriatr Soc. 2013;61(12):2087-2095. doi:10.1111/jgs.12549

21. Chen Z, Yang X, Song Y, et al. Challenges of dementia care in China. Geriatrics. 2017;2(1):7.

22. Phillipson L, Jones SC, Magee C. A review of the factors associated with the non-use of respite services by carers of people with dementia: implications for policy and practice. Health Soc Care Community. 2014;22(1):1-12. doi:10.1111/hsc. 12036

23. Tang W, Friedman DB, Kannaley K, et al. Experiences of caregivers by care recipient's health condition: a study of caregivers for Alzheimer's disease and related dementias versus other chronic conditions. Geriatr Nurs (Minneap). 2019;40(2):181-184. doi:10.1016/j. gerinurse.2018.09.012

24. Ma J, Liang L. The Evolution of China's Aged Service Supply Model. Proceedings of the 2019 4th International Conference on Humanities Science and Society Development (ICHSSD 2019). 2019 Oct 7; Advances in Social Science, Education and Humanities Research. Paris: French: Atlantis Press; 2006.

25. Thompson T, Rodebaugh TL, Pérez M, Schootman M, Jeffe DB. Perceived social support change in patients with early stage breast cancer and controls. Health Psychol. 2013;32(8):886-895. doi:10.1037/a0031894

26. Røthing M, Malterud K, Frich JC. Balancing needs as a family caregiver in Huntington's disease: a qualitative interview study. Health Soc Care Community. 2015;32(8):569-576. doi:10.1111/hsc.12174

27. Schroevers MJ, Helgeson VS, Sanderman R, Ranchor AV. Type of social support matters for prediction of posttraumatic growth among cancer survivors. Psycho-Oncology. 2010;19(1):46-53.

28. Mickelson KD, Kubzansky LD. Social distribution of social support: the mediating role of life events. Am J Community Psychol. 2003;32 (3-4):265-281. doi:10.1023/B:AJCP.0000004747.99099.7e

29. Tan EY, de Vugt ME, Köhler S, Verhey FR, Schols JM. Importance of social support within the nursing staff on agitation in residents with dementia. J Am Med Dir Assoc. 2019;20(6):785-786. doi:10.1016/j.jamda.2019.03.002
30. Barg FK, Cronholm PF, Straton JB, et al. Unmet psychosocial needs of Pennsylvanians with cancer: 1986-2005. Cancer. 2007;110 (3):631-639. doi:10.1002/cncr.22820

31. ES KIM, Bayles KA. Communication in late-stage Alzheimer's disease: relation to functional markers of disease severity. Alzheimer's Care Today. 2007;8(1):43-52.

32. Acton GJ, Yauk S, Hopkins BA, et al. Increasing social communication in persons with dementia. Res Theory Nurs Pract. 2007;21 (1):32-44. doi:10.1891/rtnpij-v21i1a005

33. Wang J, Lily Dongxia X, Xiaomei L. Health professionals' perceptions of developing dementia services in primary care settings in China: a qualitative study. Aging Ment Health. 2019;23(4):447-454.

34. Wang Y, Xiao LD, Luo Y, Xiao SY, Whitehead C. Community health professionals' dementia knowledge, attitudes and care approach: a cross-sectional survey in Changsha, China. BMC Geriatr. 2018;18 (1): 122 .

35. Zank S, Leipold B. The relationship between severity of dementia and subjective well-being. Aging Ment Health. 2001;5(2):191-196. doi:10.1080/13607860120038375

36. Yeh SCJ, Liu YY. Influence of social support on cognitive function in the elderly. BMC Health Serv Res. 2003;3(1):9.

37. Hsieh HF, Shannon SE. Three approaches to qualitative content analysis. Qual Health Res. 2005;15(9):1277-1288. doi:10.1177/ 1049732305276687

38. Kales HC, Gitlin LN, Lyketsos CG. Assessment and management of behavioral and psychological symptoms of dementia. BMJ. 2015;350 (mar02 7):h369. doi:10.1136/bmj.h369

39. Haibo X, Shifu X, Pin NT, et al. Prevalence and severity of behavioral and psychological symptoms of dementia (BPSD) in community dwelling Chinese: findings from the Shanghai three districts study. Aging Ment Health. 2013;17(6):748-752. doi:10.1080/ 13607863.2013.781116

40. Gruskin DC, Rosenberg MD, Holmes AJ. Relationships between depressive symptoms and brain responses during emotional movie viewing emerge in adolescence. Bio Rxiv. 2019;116217.

41. Conde-Sala JL, Reñé-Ramírez R, Turró-Garriga O. Severity of dementia, anosognosia, and depression in relation to the quality of life of patients with Alzheimer disease: discrepancies between patients and caregivers. Am J Geriatr Psychiatry. 2014;22 (2):138-147. doi:10.1016/j.jagp.2012.07.001

42. Sturm VE, Yokoyama JS, Eckart JA, et al. Damage to left frontal regulatory circuits produces greater positive emotional reactivity in frontotemporal dementia. Cortex. 2015;64:55-67. doi:10.1016/j. cortex.2014.10.002

43. Cheston R, Dodd E, Christopher G, Jones C, Wildschut T, Sedikides C. Selective forgetting of self-threatening statements: mnemic neglect for dementia information in people with mild dementia. Int J Geriatr Psychiatry. 2018;33(8):1065-1073. doi:10.1002/ gps.4894

44. Hodgson NA, Black BS, Johnston D, et al. Comparison of unmet care needs across the dementia trajectory: findings from the maximizing independence at home study. J Geriatr Palliat Care. 2014;2(2):5.

45. Chen HM, Huang MF, Yeh YC, et al. Effectiveness of coping strategies intervention on caregiver burden among caregivers of elderly patients with dementia. Psychogeriatrics. 2015;15(1):20-25. doi:10.1111/psyg. 12071

46. Ellis M, Astell A. Communicating with people living with dementia who are nonverbal: the creation of adaptive interaction. PLoS One. 2017;12(8):e0180395. doi:10.1371/journal.pone.0180395

47. Flicker L. Dementia reconsidered: the person comes first. $B M J$. 1999;318(7187):880A. doi:10.1136/bmj.318.7187.880a

48. Klimova B, Kuca K. Speech and language impairments in dementia. J Appl Biomed. 2016;14(2):97-103. doi:10.1016/j.jab.2016.02.002

49. Talbot R, Brewer G. Care assistant experiences of dementia care in long-term nursing and residential care environments. Dementia. 2016;15(6):1737-1754. doi:10.1177/1471301215576416 
50. Xu Z, Rüsch N, Huang F, Kösters M. Challenging mental health related stigma in China: systematic review and meta-analysis. I. Interventions among the general public. Psychiatry Res. 2017;255:449-456. doi:10.1016/j.psychres.2017.01.008

51. Bayles KA, Tomoeda CK, Cruz RF, Mahendra N. Communication abilities of individuals with late-stage Alzheimer disease. Alzheimer Dis Assoc Disord. 2000;14(3):176-181. doi:10.1097/00002093200007000-00009

52. Morris JC. Clinical dementia rating: a reliable and valid diagnostic and staging measure for dementia of the Alzheimer type. Int Psychogeriatr. 1997;9(S1):173-176. doi:10.1017/S1041610297004870

53. Leung VPY, Lam LCW, H F K C, et al. Validation study of the Chinese version of the neuropsychiatric inventory (CNPI). Int J Geriatr Psychiatry. 2001;16(8):789-793. doi:10.1002/gps.427
54. Katzman R, Zhang M, Wang Z, et al. A Chinese version of the mini-mental state examination; impact of illiteracy in a shanghai dementia survey. J Clin Epidemiol. 1988;41(10):971-978.

55. Cohen S, Mermelstein R, Kamarck T, Hoberman HM. Measuring the functional components of social support. In: Sarason IG, Sarason BR, editors. Social Support: Theory, Research, and Applications. The Hague, Holland: Martinus Nijhoff; 1985:73-94.

56. Juva K, Mäkelä M, Erkinjuntti T, et al. Functional assessment scales in detecting dementia. Age Ageing. 1997;26(5):393-400. doi:10.1093/ageing/26.5.393
Clinical Interventions in Aging

\section{Publish your work in this journal}

Clinical Interventions in Aging is an international, peer-reviewed journal focusing on evidence-based reports on the value or lack thereof of treatments intended to prevent or delay the onset of maladaptive correlates of aging in human beings. This journal is indexed on PubMed Central, MedLine, CAS, Scopus and the Elsevier
Bibliographic databases. The manuscript management system is completely online and includes a very quick and fair peer-review system, which is all easy to use. Visit http://www.dovepress.com/ testimonials.php to read real quotes from published authors. 